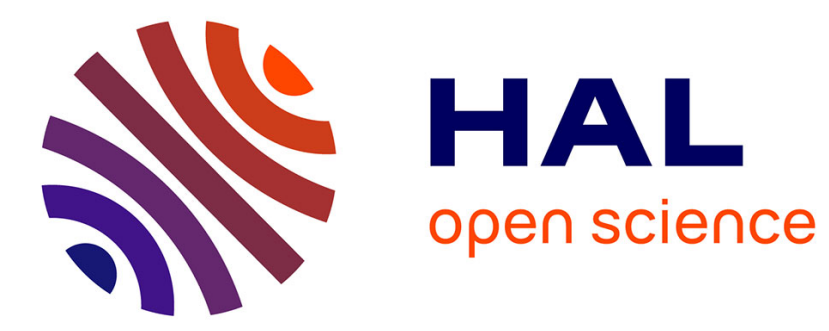

\title{
An approximate model for optimizing Bernoulli columns against buckling
}

E. Ruocco, C. M. Wang, H. Zhang, Noël Challamel

\section{To cite this version:}

E. Ruocco, C. M. Wang, H. Zhang, Noël Challamel. An approximate model for optimizing Bernoulli columns against buckling. 10.1016/j.engstruct.2017.01.077 . hal-01693905

Engineering Structures, 2017, 141, pp.316-327.

HAL Id: hal-01693905

https://hal.science/hal-01693905

Submitted on 31 Dec 2019

HAL is a multi-disciplinary open access archive for the deposit and dissemination of scientific research documents, whether they are published or not. The documents may come from teaching and research institutions in France or abroad, or from public or private research centers.
L'archive ouverte pluridisciplinaire HAL, est destinée au dépôt et à la diffusion de documents scientifiques de niveau recherche, publiés ou non, émanant des établissements d'enseignement et de recherche français ou étrangers, des laboratoires publics ou privés. 


\title{
An approximate model for optimizing Bernoulli columns against buckling
}

\author{
E. Ruocco ${ }^{\mathrm{a}, *}$, C.M. Wang ${ }^{\mathrm{b}}$, H. Zhang ${ }^{\mathrm{c}}$, N. Challamel ${ }^{\mathrm{d}}$ \\ a Department of Ingegneria Civile, Design, Edilizia e Ambiente, University of Campania “Luigi Vanvitelli", Via Roma 29, 81031 Aversa, Ce, Italy \\ ${ }^{\mathrm{b}}$ School of Civil Engineering, University of Queensland, St Lucia, Queensland 4072, Australia \\ ${ }^{c}$ Department of Civil and Environmental Engineering, National University of Singapore, Kent Ridge, Singapore 119260, Singapore \\ ${ }^{\mathrm{d}}$ Université de Bretagne Sud, Institut de Recherche Dupuy de Lôme (IRDL), Centre de Recherche, Rue de Saint Maudé, BP92116, 56321 Lorient Cedex, France
}

\begin{abstract}
Proposed herein is a simple but powerful method for optimization of inhomogeneous, elastically restrained columns against buckling when subjected to both compressive concentrated and distributed axial loads that include self-weight. Unlike previously published studies on the subject, we do not have to specify any prescribed geometrical variation and analysis may be readily performed on columns with any complex geometrical shape. In the proposed method, the differential equation governing the buckling of Euler columns is discretized by adopting the Hencky bar-chain model, and critical buckling loads are evaluated by seeking the lowest eigenvalue of the resulting system of algebraic equations. The discrete nature of the formulation, as well as the reduced number of parameters to be optimized, is well suited for the adopted optimization process that is based on evolutionary algorithms. We propose an optimization scheme based on a parallel genetic algorithm. A comparison study between the obtained optimal column shape and buckling loads on homogeneous and isotropic columns with circular cross section, and the numerical and analytical solutions found in the open literature shows fast convergence, high accuracy and flexibility of the proposed method.
\end{abstract}

\section{Introduction}

Structural optimization has become increasingly important as modern sustainable construction demands engineers to curb wastage of materials and to use optimal structural member shapes and topologies, in order to achieve light weight and yet possessing high strength and meeting serviceability requirements. The optimal design of axially compressed, non-uniform columns plays a key role for engineering structures, because of the wide applications of columns and bracing elements in mechanical engineering, civil and construction industries. Many researchers have studied the buckling load and the corresponding buckling mode of nonuniform columns. Among others, Eisenberger [1] presented exact buckling loads for columns with variable cross section and loaded by axial forces that vary according to a polynomial law along the column length. By posing it as an inverse buckling problem, Elishakoff [2] derived closed form solutions for buckling of simply

\footnotetext{
* Corresponding author.

E-mail addresses: eugenio.ruocco@unicampania.it (E. Ruocco), cm.wang@uq. edu.au (C.M. Wang), zhanghong@u.nus.edu (H. Zhang), noel.challamel@univ-ubs.fr
} (N. Challamel). supported columns with variable stiffness. Ruocco et al. [3-5] proposed a semi-analytical approach for obtaining a buckling solution of non-uniform beams.

In general, it is difficult to obtain a closed form solution for the differential equation governing the buckling behaviour of arbitrarily shaped columns. Consequently, most of the studies proposed a discretized form of the governing equation so that the unknown displacement of the column may be confined to seeking a finite number of parameters describing the deflection. In other words, the governing differential equation can be transformed into a system of algebraic equations with unknown coefficients. For instance, Li [6] proposed a displacement field as a linear combination of a Fourier series and an auxiliary polynomial function for solving the free vibration of beams with any boundary conditions. Recently, Huang and Luo [7] proposed a simple method to determine the critical load for axially inhomogeneous beams, restrained under several typical end supports, by expanding the mode shape as a power series. Within this thematic ambit, one can include the work of Hencky [8] in which in 1920, he proposed a discretized form of the elastica studied by Euler almost two centuries ago by replacing the continuum beam with a finite number of rigid beam elements connected together by elastic rotational springs. In this pioneering 


\section{Nomenclature}

$L \quad$ column length

$F_{i} \quad$ compressive concentrated axial loads

$p(x) \quad$ distributed axial load

$\rho(x) \quad$ beam density

$\chi(x) \quad$ self-weight

$\chi_{0} \quad$ value of self-weight at $x=0$

$\bar{\chi}=\chi_{0}^{c r} L^{3} / \rho E I_{0}$ non-dimensional critical self-weight

$P_{j}=\sum_{i=0}^{j} F_{i}+\int_{a_{i}} p_{i}(x) d x$ equivalent concentrated axial forces

$\left(K_{R A}, K_{R B}, K_{L A}, K_{L B}\right)$ stiffness of lateral springs

$\left(s_{X}, s_{Z}\right) \quad$ displacement field

$(u, w) \quad$ generalized displacement

$\Omega_{L} \quad$ linear strain energy

work, Hencky solved the buckling problem of a beam by considering 2, 3 and 4 rigid elements, and observing that the discrete model converges to the Euler continuum solution in the limiting case of infinite elements. Many researchers showed interest in the numerical and theoretical aspects of Hencky's work. Silverman [9] pointed out that the central finite difference beam model is mathematically equivalent to the Hencky bar chain model for the buckling problem if the nodal spacing of the finite difference model takes on the same length of the rigid beam segments. Later, Leckie and Lindberg [10] pointed the equivalence of the central finite difference beam model and the Hencky bar-chain model for vibration problems. Recently, Challamel et al. [11] showed that this discrete problem was mathematically similar to the vibrations equations of a discrete string, whose exact solution was first given by Lagrange, whereas Wang et al. [12] and Duan and Wang [13] revisited the study on both buckling and vibration problems of Hencky-bar chain for various boundary conditions with elastic end restraints.

Studies on optimal column design against buckling have a very long history. Since the pioneering work of Lagrange in 1773 [14] where he first tried to determine the optimal shape of a thin elastic clamped column, a noticeable number of papers have been devoted to the optimization of columns against buckling. Clausen obtained the first correct results almost a century later [15]. Keller [16] determined the optimal cross sectional variation of elastic columns of a given length and volume that maximizes the buckling load. Whilst Keller treated pinned ended columns, Tadjbakhsh and Keller [17] obtained solutions for clamped-free and clamped-pinned columns. Olhoff and Seyranian [18], Seyranian [19] and Olhoff and Rasmussen [20] showed that for clamped ended columns, the optimal shape is associated with a bimodal fundamental buckling mode and proposed a mathematical formulation of the optimization problem able to take into account this bimodal behaviour. Li et al. [21] studied the optimization problem of a composite column under an end concentrated load and a distributed axial load, by considering a bending stiffness that has a polynomial order variation. Maalawi [22] determined the exact cross-sectional configuration of stepwise clamped columns for maximum buckling load for any number of segments. Atanackovic and Simic [23] determined the optimal shape of a simply supported column loaded by uniformly distributed load. Novakovic [24] determined the optimal shape of an elastic beam resting on Winkler foundation.

The objective of the present optimization problem is to maximize the critical buckling load of a column for a given volume and length with or without a shape constraint. The discrete nature of the formulation enables the optimization problem to be reduced to seeking the optimal values of a finite number of parameters. This is well suited for an optimization process that is based on genetic algorithms (GA). Proposed by Holland [25] in the early $1970 \mathrm{~s}$ and
$\Omega_{N L} \quad$ non-linear potential energy

$E(x, y, z)$ Young's modulus

$A(x) \quad$ cross sectional area

$(E A(x), E I(x))$ longitudinal and bending beam stiffnesses

$n$ number of rigid segments in Hencky bar-chain model

$a=L / n \quad$ segmental length in Hencky bar-chain model

$C_{j}=E I_{j} / a$ bending stiffness in Hencky bar-chain model

$\alpha_{j}=P_{j} a^{2} / E I_{j}$ non-dimensional axial load

$\xi=x / L$ non-dimensional coordinate

$(S, C, F)$ simple Supported, Clamped, Free boundary conditions

$\lambda \quad$ partially constrained beam length

$\Pi=P_{c r} / P_{\text {hom }}$ non-dimensional concentrated critical load

$\Theta=q_{c r} / q_{\text {hom }}$ non-dimensional distributed critical load

put into practical applications in the late $1980 \mathrm{~s}, \mathrm{GA}$ are inspired by biological evolution and they have proven to be robust and powerful adaptive search techniques [26]. Unlike previous studies, there is no need for any a priori law ruling the geometrical variation, and also analysis can be easily performed on complex geometrical shapes. GA is widely considered as an effective optimization tool in term of solution reliability and convergence rate. Recently, Nguyen et al. [27] proposed a vibration and lateral buckling GA optimization of thin-walled laminated composite beams with channel sections, by considering flanges width, web height and fibre orientation as the design variables. Iuspa and Ruocco [28] and, more recently, Ehsani and Rezaeepazhand [29] proposed the stacking sequence optimization of laminated plates for maximum buckling load using GA.

In this paper, we adopt an enhanced Hencky bar-chain model (HBM) for buckling optimization of non-uniform columns subjected to both compressive axial concentrated loads and distributed axial loads that include selfweight. The work extends an optimization analysis based on discrete parameters recently published [30], by considering general geometrical shape, loading and boundary conditions. In order to assess the accuracy and the robustness of the Hencky bar chain model - genetic algorithm technique (HBM-GA) for column optimization against buckling, comparison studies with available numerical and/or analytical results are conducted.

\section{Hencky bar-chain model}

Consider a non-uniform column of length $L$, subjected to compressive concentrated axial loads $F_{i}$ applied on $L_{i}$ and a distributed axial load $p(x)$. The column ends are restrained by rotational and lateral springs with stiffnesses $\left(K_{R A}, K_{R B}\right)$ and $\left(K_{L A}, K_{L B}\right)$, respectively (see Fig. 1).According to the Euler-Bernoulli column model, the displacement field $\mathbf{s}=\left[s_{x}(x, z) s_{z}(x, z)\right]^{T}$ is governed by the generalized displacement components $u=u(x)$ and $w=w(x)$, which are given by:

$s_{x}(x, y, z)=u-z w,_{x}$

$s_{z}(x, y, z)=w$

where $w_{x}$ denotes $\partial w / \partial x$.

The equilibrium equation can be obtained by invoking the principle of minimum potential energy. The elastic strain energy is given by:

$$
\begin{aligned}
\Omega_{L} & =\frac{1}{2} \int_{V} \varepsilon_{L} \sigma_{L} d V=\frac{1}{2} \int_{V} E(x, y, z)\left(u,_{x}-z w,_{x x}\right)^{2} \\
& =\frac{1}{2} \int_{l} E A u,_{x}^{2}+E I w_{, x x}^{2} d x
\end{aligned}
$$




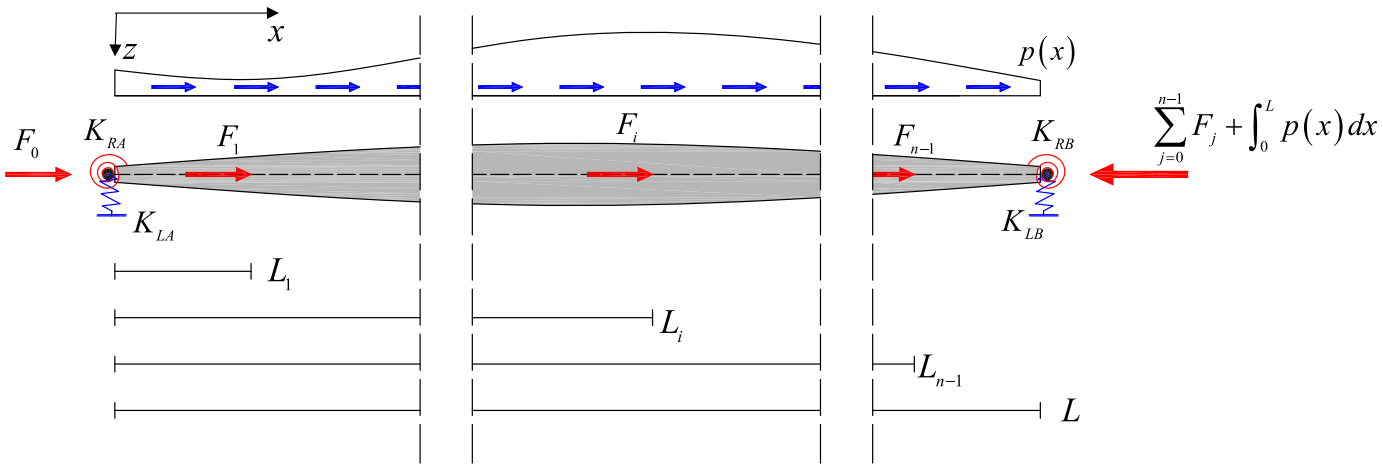

Fig. 1. Non-uniform column subject to distributed and concentrated axial loads.

and the potential energy of the axial stress is given by:

$\Omega_{N L}=\frac{1}{2} \int_{l} \sigma_{x} A w,_{x}^{2} d x$

In Eqs. (2) and (3), $E(x, y, z)$ is the Young's modulus and

$(E A(x), E I(x))=\int_{A}\left(1, z^{2}\right) E(x, y, z) d A$

are the longitudinal and bending beam rigidities, respectively.

According to the Hencky bar chain model (HBM), the continuous column is replaced with a discrete model made from $n$ rigid segments with intermediate elastic rotational springs having stiffnesses $C_{j}=E I_{j} / a$ (Fig. 2). The flexural rigidities $E I_{0}=E I$ at $x=0$, $E I_{n}=E I$ at $x=L$ and $E I_{j}=E I$ at $x=j a$ for $1 \leqslant j \leqslant n-1$. The segmental length, represented in Fig. 3, is denoted by $a=L / n$.

We represent both the distributed load $p(x)$ and concentrated load forces $F_{i}$ of the continuous column by the following equivalent concentrated force $P_{i}$ :

$P_{0}=F_{0}$

$P_{1}=F_{0}+F_{1}+\int_{a_{1}} p_{1}(x) d x$

$P_{j}=\sum_{i=0}^{j} F_{i}+\int_{a_{i}} p_{i}(x) d x$

on the discrete model as shown in Fig. 3. The correspondence between the continuous and the discrete models also requires a transformation of the lateral springs $\left(K_{R}, K_{L}\right)$, that assume the values $\left(C_{R}, C_{L}\right)[31]$.
Under the Hencky bar-chain assumptions, the principle of minimum total potential energy assumes the following discretized form [32]:

$$
\begin{aligned}
\frac{\delta\left(\Omega_{L}+\Omega_{N L}\right)}{\delta w_{i}} & =0 \Rightarrow \quad \phi_{i} w_{i-2}+\gamma_{i} w_{i-1}+\eta_{i} w_{i}+\kappa_{i} w_{i+1}+w_{i+2} \\
& =0 \quad(i=2, \ldots, n-2)
\end{aligned}
$$

and the boundary conditions are given by

$$
\begin{aligned}
& \eta_{0} w_{0}+\kappa_{0} w_{1}+w_{2}=0 \\
& \gamma_{1} w_{0}+\eta_{1} w_{1}+\kappa_{1} w_{2}+w_{3}=0
\end{aligned}
$$

and

$$
\begin{aligned}
& w_{n-3}+\gamma_{n-1} w_{n-2}+\eta_{n-1} w_{n-1}+\kappa_{n-1} w_{n}=0 \\
& w_{n-2}+\eta_{n} w_{n-1}+\kappa_{n} w_{n}=0
\end{aligned}
$$

In Eqs. (6)-(8) the known terms $\left(\phi_{i}, \gamma_{i}, \kappa_{i}, \eta_{i}\right)$ are constant depending by the applied loads $P_{j}$, defined in [31] and reported in Appendix A for sake of completeness.

Eqs. (6)-(8) may be collected in the following matrix form:

$\mathbf{K}\left(P_{j}\right) \cdot \mathbf{w}=0$

For a nontrivial buckling solution, the determinant of the matrix K must vanish, i.e.

$\operatorname{det}(K)=0$

One obtains the critical buckling load by solving the characteristic Eq. (10) for the lowest positive root.
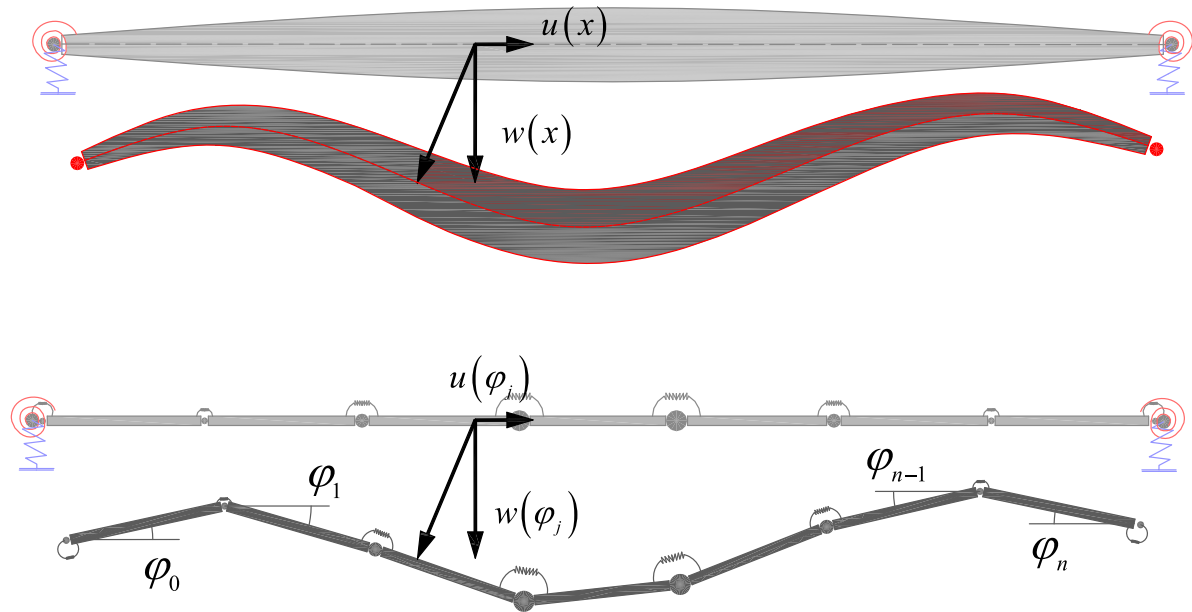

Fig. 2. Continuous model and equivalent discrete model. 

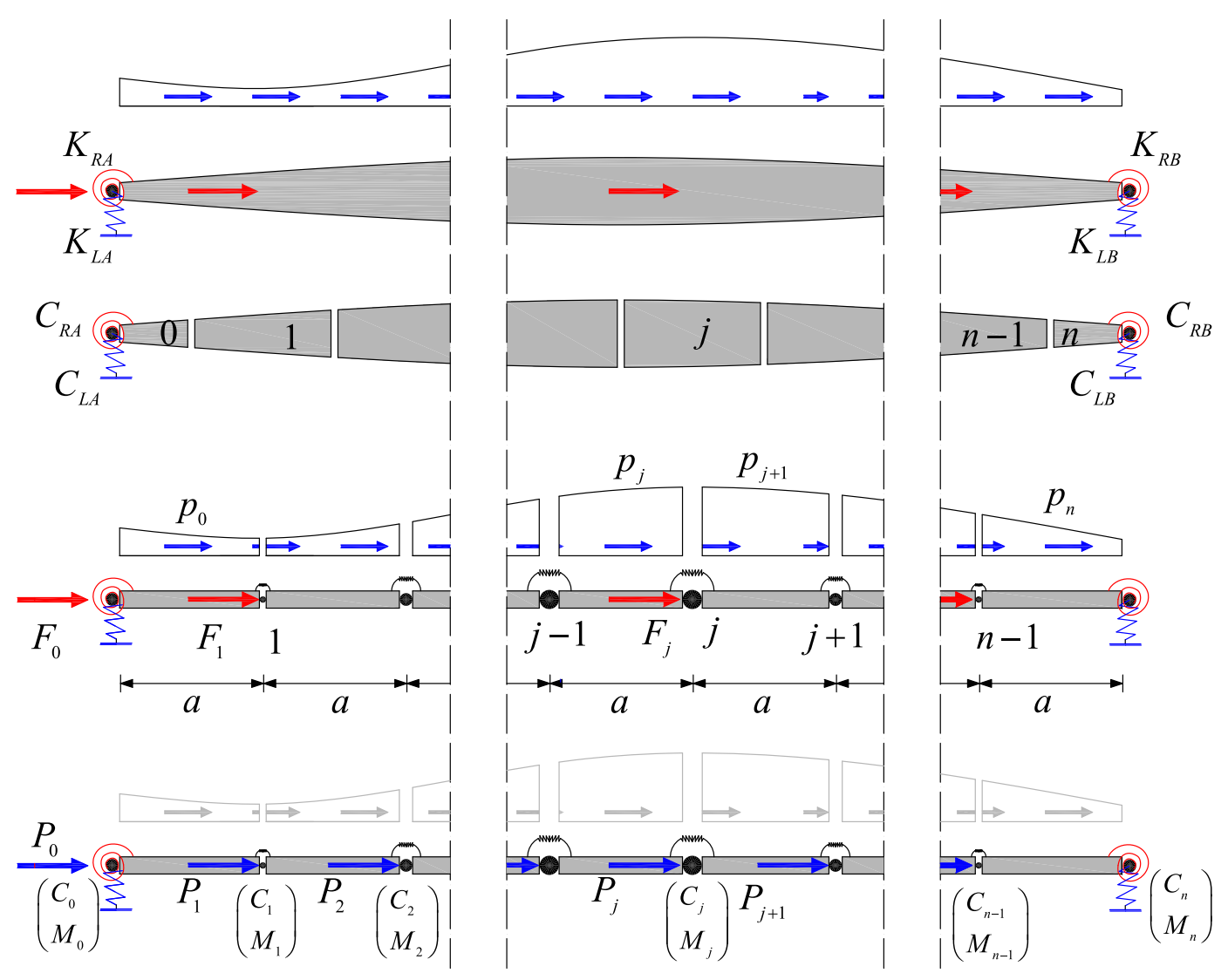

Fig. 3. Discretized Hencky bar-chain model.

\section{Optimization problem}

Because of their tailorability, composite materials can be configured to accomplish the highest structural responses with specific design requirements. Such an optimal configuration can be obtained through an optimization process, in which we maximize the critical buckling load of the column for a given structural area defined as the sum of the discrete areas $A_{i}(i=0,1, \ldots, n)$ (or the corresponding total volume $V=\sum_{i=1}^{n-1} A_{i} a+\frac{a}{2}\left(A_{0}+A_{n}\right)$, by assuming that the column is made of a homogenous material) related to the HBM model. In such an approach, the discrete crosssectional areas $A_{i}$ have been adopted as design variables, and the second moment of area $I_{i}$ is related to the cross-sectional area by:

$I_{i}=c A_{i}^{\zeta}$

with $(c, \zeta)$ constants associated with the cross sectional shape [33]. If unconstrained, the optimization process furnishes the optimal values $A_{i}$ while maintaining a constant volume. If there are additional constraints such as prescribed cross-section $\lambda$ over a portion of the column, then the cross-sectional areas are characterized by pre-assigned values that do not change in the optimization process. Material properties, cross-sectional shape and boundary conditions are given parameters in the optimisation problem. Since the study searches for the maximum buckling load of non-uniform column, the buckling load has been considered as fitness function, and the Genetic Algorithm was applied to optimize the discrete spring stiffness values of HBM that define the shape of the non-uniform column. GA is a population-based metaheuristic method based on the evolutionary ideas of natural selection and genetics. GA has the advantages of avoiding being trapped in a local optimal solution and being able to handle discrete functions without any derivatives or auxiliary information.

A parallel calculation allows us to decrease the optimization time, maintaining at the same time a number of variables sufficient to represent a large range of configurations [34]. In order to verify the convergence response of the method, four independent populations of 200 individuals have been carried out, and the average distance compared for all the obtained results. The initial population is randomly generated in the solution space. Elitist selection, tournament selection, crossover and mutation are the operators used to generate the next generations. Elitist generation is a selection strategy where a limited number of individuals (10\% in our case) with the best fitness values are chosen to pass the next generation, avoiding the crossover and the mutation operators. For the tournament selection, applied to the $5 \%$ of the population, two chromosomes in the current population are randomly paired and, in each couple, the one that possesses the largest fitness function is copied to the next generation. The two-point crossover method is employed to interchange and combine the genes between individuals, whereas the mutation is used for nurture the genetic diversity. A hundred generations is taken as the stopping criteria.

\section{Example problems considered}

Numerical analyses were carried out to validate the efficiency and to show the potential of the present HBM-GA method. The columns are subjected to concentrated axial loads $\left(F_{0}, F_{1}, \ldots F_{n}\right)$ applied on each segment of Hencky-bar chain, as well as to distributed axial load conditions $q$ and self-weight $\chi$ (Fig. 4).

The analyses were performed for $10,20,40$ and 60 segments in HBM. The results show the general form of the optimal column 


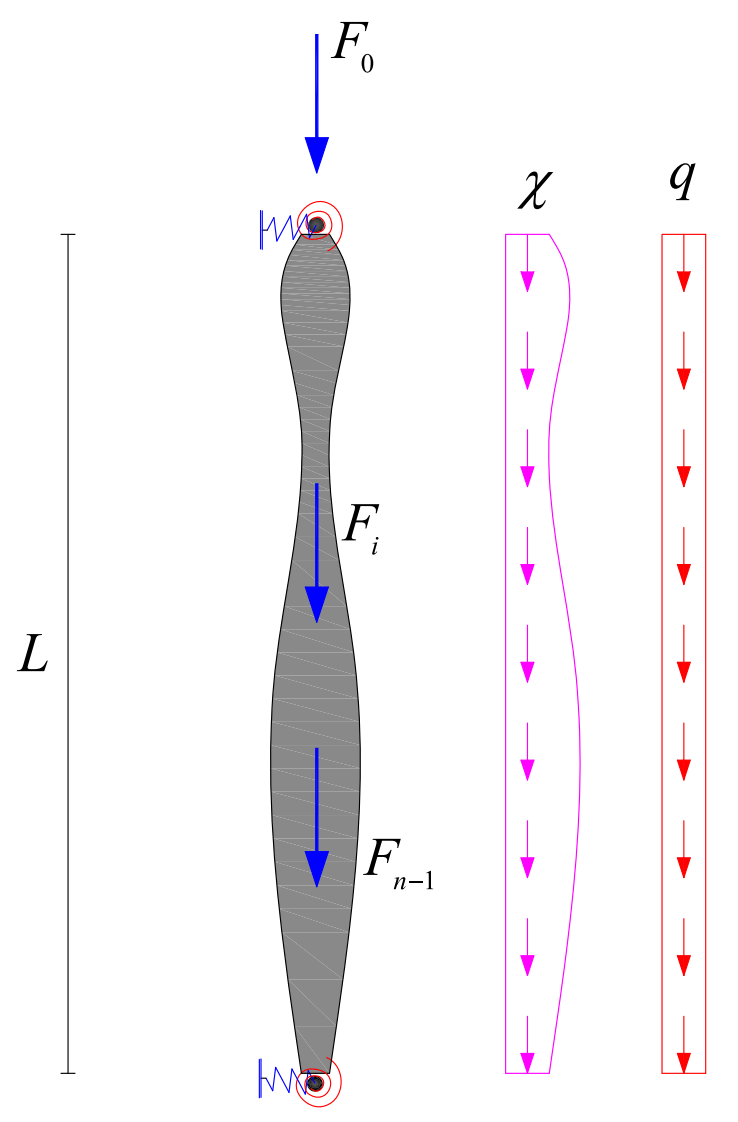

Fig. 4. Load conditions considered. shape, even when the number of segments is as low as 20. Clearly, for more complicated column shapes, 20 segments are not sufficient. However, 40 segments should suffice in furnishing a reasonably clear optimal shape for the column.For the sake of simplicity but without loss of generality, a circular cross-section has been adopted, and the results have been reported in terms of the nondimensional radius $r / r_{0}$, where $r$ is the radius of the optimal circular cross-section and $r_{0}$ the radius corresponding to the uniform column with same volume and length. The beam distance $x$ is represented in non-dimensional coordinate $\xi=x / L$.The optimal column design can then be represented by its radial profile as shown in Fig. 5.

\subsection{Example 1. Optimization of columns under concentrated end load}

The first example is concerned with the optimization of a nonuniform column subjected to a concentrated end force $F_{0}$ (see Fig. 4). By using the HBM-GA method, the maximum buckling loads for optimal column shapes with $n$ varying between 10 and 60 and various boundary conditions are presented in Table 1 . The buckling analysis has been performed on a quad-core Intel Core i7 $2.71 \mathrm{GHz}$ processor, using a homemade Matlab code that necessitates about $(4.76,8.54,18.90,34.02)$ seconds for completing the 200 buckling analysis, required for a single generation in the GA process, with $(10,20,40,60)$ elements. By using the four processors in parallel, the 100 generations in the optimization analysis require almost $5 \mathrm{~min}$ for optimization process considering 10 elements and almost 45 min considering 60 elements.

In Table 1 , the non-dimensional maximum buckling load parameter $\Pi$ is the normalized maximum buckling load $P_{c r}$ by the buckling load $P_{\text {hom }}$ of the corresponding uniform column with the same volume, length and boundary conditions, i.e.
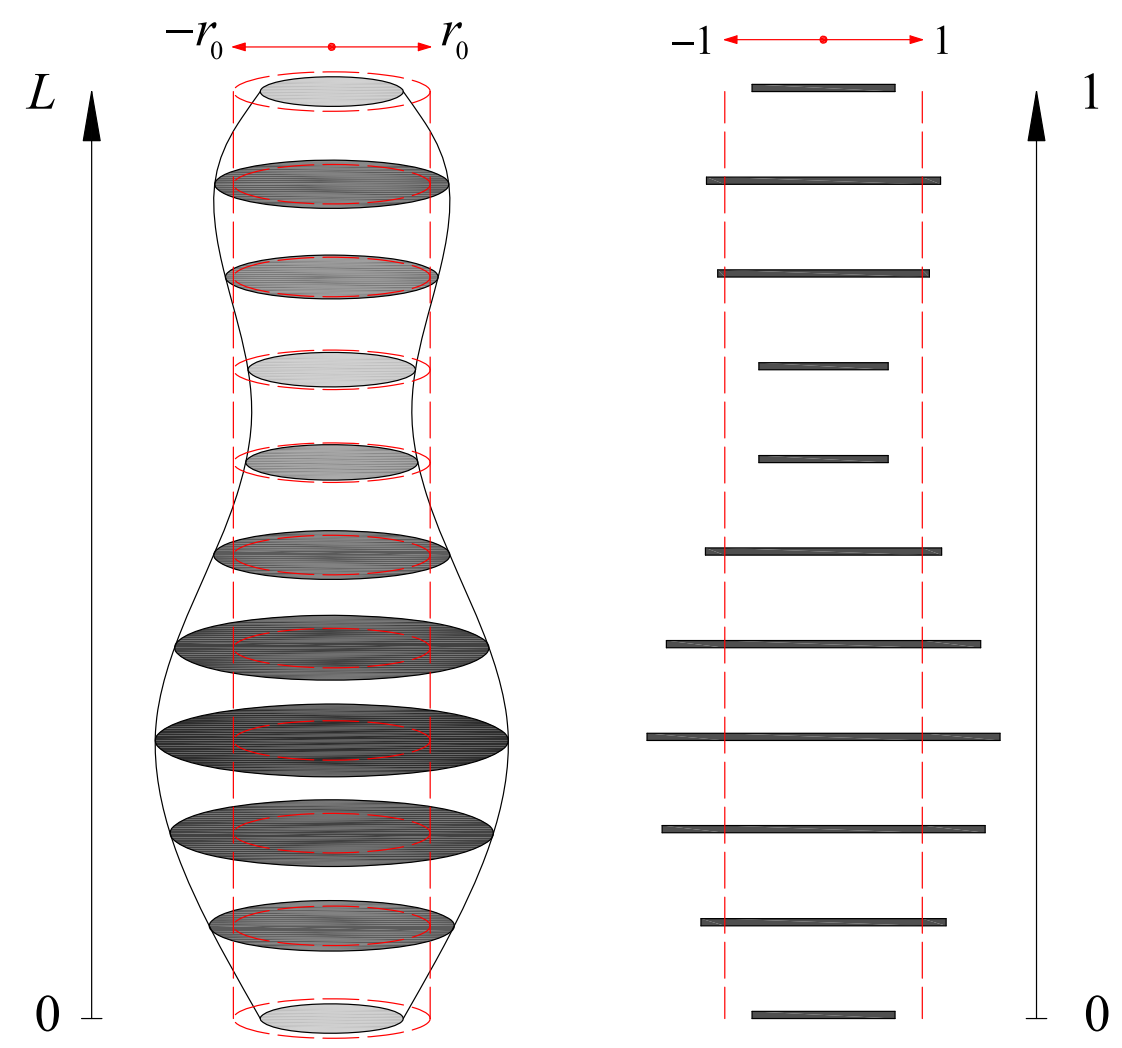

Fig. 5. Representation of optimal column shape in non-dimensional coordinate $\xi=x / L$ and radius $\mathrm{r} / \mathrm{r}_{0}$. 
Table 1

Maximum buckling load parameter $\Pi$ for $n$-segments HBM with various boundary conditions.

\begin{tabular}{|c|c|c|c|c|c|c|c|c|c|}
\hline \multicolumn{5}{|c|}{ HBM-GA } & \multicolumn{5}{|c|}{ Previous researchers } \\
\hline B.C. & $n=10$ & $n=20$ & $n=40$ & $n=60$ & [16] & {$[17]$} & {$[21]$} & [18] & [20] \\
\hline SS & 1.399 & 1.349 & 1.336 & 1.333 & 1.334 & - & - & - & - \\
\hline $\mathrm{CF}$ & 1.412 & 1.393 & 1.372 & 1.345 & - & 1.333 & 1.3204 & - & - \\
\hline CS & 1.435 & 1.412 & 1.398 & 1.376 & - & 1.351 & - & 1.34 & - \\
\hline CC & 1.398 & 1.376 & 1.328 & 1.322 & - & - & - & 1.32 & 1.3262 \\
\hline
\end{tabular}

$\Pi=\frac{P_{c r}}{P_{\text {hom }}}$

Note that $P_{\text {hom }}=\kappa \pi^{2} E I / L^{2}$ and $\kappa=1,0.25,2.046$ and 4 for simply supported ends (SS), clamped-free ends (CF), clamped-simply supported ends (CS) and clamped-clamped ends, respectively.

For SS columns, a comparison of the maximum buckling loads with the global optimal buckling load obtained by Keller [16] shows that $n<40$ segments is not sufficient to capture the optimal column shape that furnishes the maximum possible buckling load $\Pi=4 / 3=1.3333$. One would need at least $n=60$ to get the buckling load to within $1.3 \%$ difference from the global maximum buckling load. In addition, for the proposed HBM-GA procedure, we had to impose a lower bound $A_{\min }=0.05 A_{\text {hom }}$ to prevent any vanishing cross sectional area in the internal domain of the columns. By doing so, the optimal buckling loads are somewhat lower than the buckling loads corresponding to the ideal cases. In the case of CF column, $n=40$ is adequate to furnish a buckling load that is close to the global maximum buckling load of $\Pi=1.333$ obtained by Tadjbakhsh and Keller in [17]. The buckling load of CF column obtained by Li et al. [21] is lower because they considered an area profile that varies accordingly to the following law:

$A(x)=(1+2 \eta)(1-\xi)^{\eta}$

where $\eta$ is optimized. In the case of CS column, the use of $n=40$ segments yields a buckling load that is within $0.98 \%$ difference from the global buckling load obtained by Tadjbakhsh and Keller in [17]. Finally, for CC columns, the excellent agreement with the results obtained by Olhoff and Seyranian [18] and Olhoff and Rasmussen [20] shows the capacity of the proposed approach to detect the critical behaviour of bimodal columns.
Fig. 6 shows the optimal shapes and the corresponding buckling modes of SS, CF, CS and CC columns obtained by taking 40 segments in the HBM. It is interesting to observe how the optimal column shape follows the buckling mode shape, where the mass is increased at large curvatures and decreased at small curvatures. Concerning the bimodal columns, the optimal shape, as well as the critical mode, obtained for CC columns are in agreement with ones reported in [18].

The gain in terms of maximum buckling load for the optimal non-uniform column over its uniform counterpart is 33\% at most.

The CF column has also been studied by Krishna and Ram [30], by considering a link-spring model and determining the optimal solution via solving a recursive set of equations. Their method may be regarded as a semi-analytical method. In their treatment of the CF case, they have used $(n+1)$ links instead of $n$ links and in so doing, their columns of different number of links do not have a constant volume since the volumes differ by the additional link volume. In addition, they incorrectly set the spring stiffness for the clamped end as infinitely large instead of $2 C_{0}$ [35]. Note that the stiffness for the rotational spring at the clamped end of the Euler-Bernoulli column has to take a value of $2 C_{0}$ when modelled by HBM (or link-spring system) as proven in [8] and [31].

\subsection{Example 2. Optimization of columns under uniformly distributed load}

The second example is concerned with the optimization of a non-uniform column subjected to a uniformly distributed load $q$ along its length (see Fig. 4). By using the HBM-GA method, the maximum buckling loads for optimal column shapes with $n=20$, 40 and various boundary conditions are presented in Table 2. In
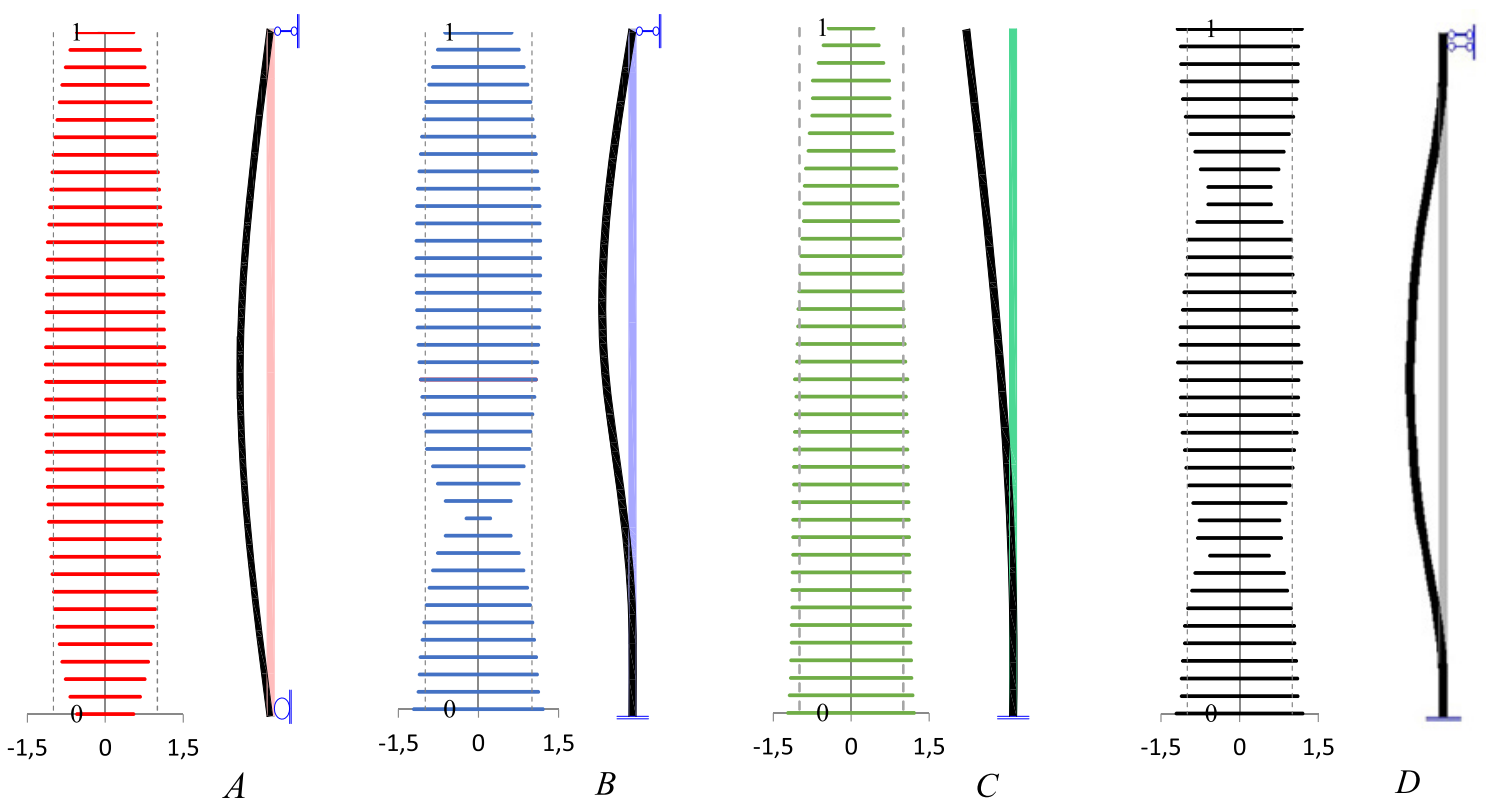

Fig. 6. Optimal shapes and buckling modes for concentrated end loaded columns with 40 segments for SS (A), CS (B), CF (C) and CC (D) boundary conditions. 
Table 2

Maximum buckling load parameter $\Theta$ for columns with various boundary conditions.

\begin{tabular}{lll}
\hline B.C. & $n=20$ & $n=40$ \\
\hline SS & 1.2243 & 1.2895 \\
CF & 1.2925 & 1.3336 \\
CS & 1.4125 & 1.5222 \\
\hline
\end{tabular}

the table, the non-dimensional maximum buckling load parameter $\Theta$ is the normalized maximum buckling load $q_{c r}$ by the buckling load $q_{\text {hom }}$ of the corresponding uniform column with the same volume, length and boundary conditions, i.e. Table 3

$\Theta=\frac{q_{c r}}{q_{\text {hom }}}$
Note that $q_{\text {hom }}$ for columns having simply supported ends (SS), clamped-free ends (CF), and clamped-simply supported ends (CS) are given in Ref. [13].

The optimal column shapes are associated with buckling loads that vary between $1.22 q_{\text {hom }}$ and $1.52 q_{\text {hom }}$ for different boundary conditions considered. As the columns subjected to a concentrated end load, the CS column gives the best performance in the increase of buckling load. Fig. 7 shows the optimal shapes of such loaded columns for various boundary conditions and by adopting 40 segments for HBM.

\subsection{Example 3. Optimization of columns under selfweight}

As an illustrative example of the potential use of the proposed methodology, let us consider the optimization of non-uniform col-

Table 3

Critical self-weight w for a column with linearly varying cross-sectional area.

\begin{tabular}{|c|c|c|c|c|c|c|}
\hline & \multirow[t]{2}{*}{ Method } & \multirow[t]{2}{*}{$N$} & \multicolumn{4}{|c|}{ Boundary conditions } \\
\hline & & & $\mathrm{CF}$ & SS & CS & CG \\
\hline \multirow[t]{4}{*}{$v=0$} & Present & 50 & 8.0728 & 18.891 & 53.683 & 75.858 \\
\hline & & 100 & 7.9950 & 18.732 & 53.104 & 75.271 \\
\hline & Ref. [13] & & 7.84 & 18.38 & 53.91 & 78.96 \\
\hline & Ref. [32] & & 7.8373 & 18.569 & 52.501 & 74.629 \\
\hline \multirow[t]{3}{*}{$v=0.2$} & Present & 50 & 8.2840 & 16.442 & 48.969 & 67.791 \\
\hline & & 100 & 8.1779 & 16.342 & 48.531 & 67.399 \\
\hline & Ref. [38] & & 8.076 & 16.237 & 48.072 & 66.694 \\
\hline \multirow[t]{3}{*}{$v=0.4$} & Present & 50 & 8.5893 & 13.834 & 43.964 & 59.253 \\
\hline & & 100 & 8.5002 & 13.781 & 43.653 & 59.036 \\
\hline & Ref. [38] & & 8.412 & 13.726 & 43.327 & 58.791 \\
\hline \multirow[t]{3}{*}{$v=0.8$} & Present & 50 & 9.9947 & 7.5331 & 31.958 & 39.055 \\
\hline & & 100 & 9.9522 & 7.5485 & 31.874 & 39.139 \\
\hline & Ref. [38] & & 9.911 & 7.564 & 31.784 & 39.178 \\
\hline
\end{tabular}
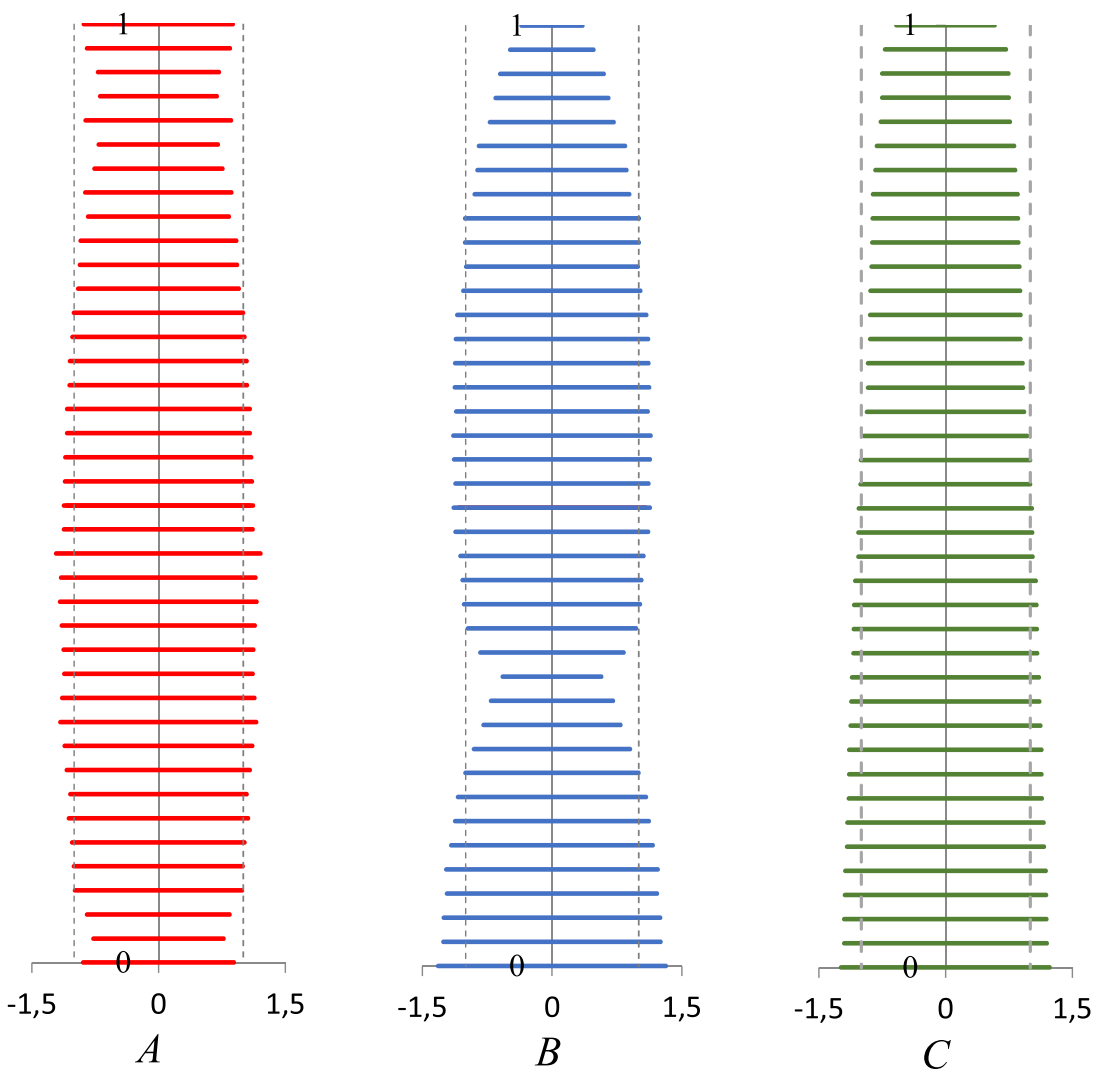

Fig. 7. Optimal shapes and buckling modes for uniformly distributed loaded columns with 40 segments for SS (A), CS (B), CF (C) boundary conditions. 
Table 4

Optimum design of stepwise CF columns.

\begin{tabular}{|c|c|c|c|c|}
\hline Stepwise column & $\mathrm{N}$ & 50 & 100 & {$[22]$} \\
\hline$s_{2}$ & $\begin{array}{l}\left(r_{1}, L_{1}\right) \\
\left(r_{2}, L_{2}\right) \\
\Pi\end{array}$ & $\begin{array}{l}(1.0776,0.72) \\
(0.7647,0.28) \\
1.2023\end{array}$ & $\begin{array}{l}(1.0783,0.72) \\
(0.7626,0.28) \\
1.2053\end{array}$ & $\begin{array}{l}(1.08,0.7245) \\
(0.75,0.2755) \\
1.2079\end{array}$ \\
\hline$s_{3}$ & $\begin{array}{l}\left(r_{1}, L_{1}\right) \\
\left(r_{2}, L_{2}\right) \\
\left(r_{3}, L_{3}\right) \\
\Pi\end{array}$ & $\begin{array}{l}(1.1032,0.58) \\
(0.9161,0.26) \\
(0.6889,0.16) \\
1.2321\end{array}$ & $\begin{array}{l}(1.1056,0.59) \\
(0.9079,0.27) \\
(0.6339,0.14) \\
1.2642\end{array}$ & $\begin{array}{l}(1.111,0.57) \\
(0.911,0.29) \\
(0.636,0.14) \\
1.2710\end{array}$ \\
\hline$s_{4}$ & $\begin{array}{l}\left(r_{1}, L_{1}\right) \\
\left(r_{2}, L_{2}\right) \\
\left(r_{3}, L_{3}\right) \\
\left(r_{4}, L_{4}\right) \\
\Pi\end{array}$ & $\begin{array}{l}(1.1209,0.48) \\
(0.9961,0.24) \\
(0.8423,0.16) \\
(0.6142,0.12) \\
1.2819\end{array}$ & $\begin{array}{l}(1.1177,0.52) \\
(0.9695,0.25) \\
(0.7880,0.14) \\
(0.5625,0.09) \\
1.2886\end{array}$ & $\begin{array}{l}(1.125,0.475) \\
(1.000,0.275) \\
(0.775,0.175) \\
(0.500,0.075) \\
1.2914\end{array}$ \\
\hline
\end{tabular}
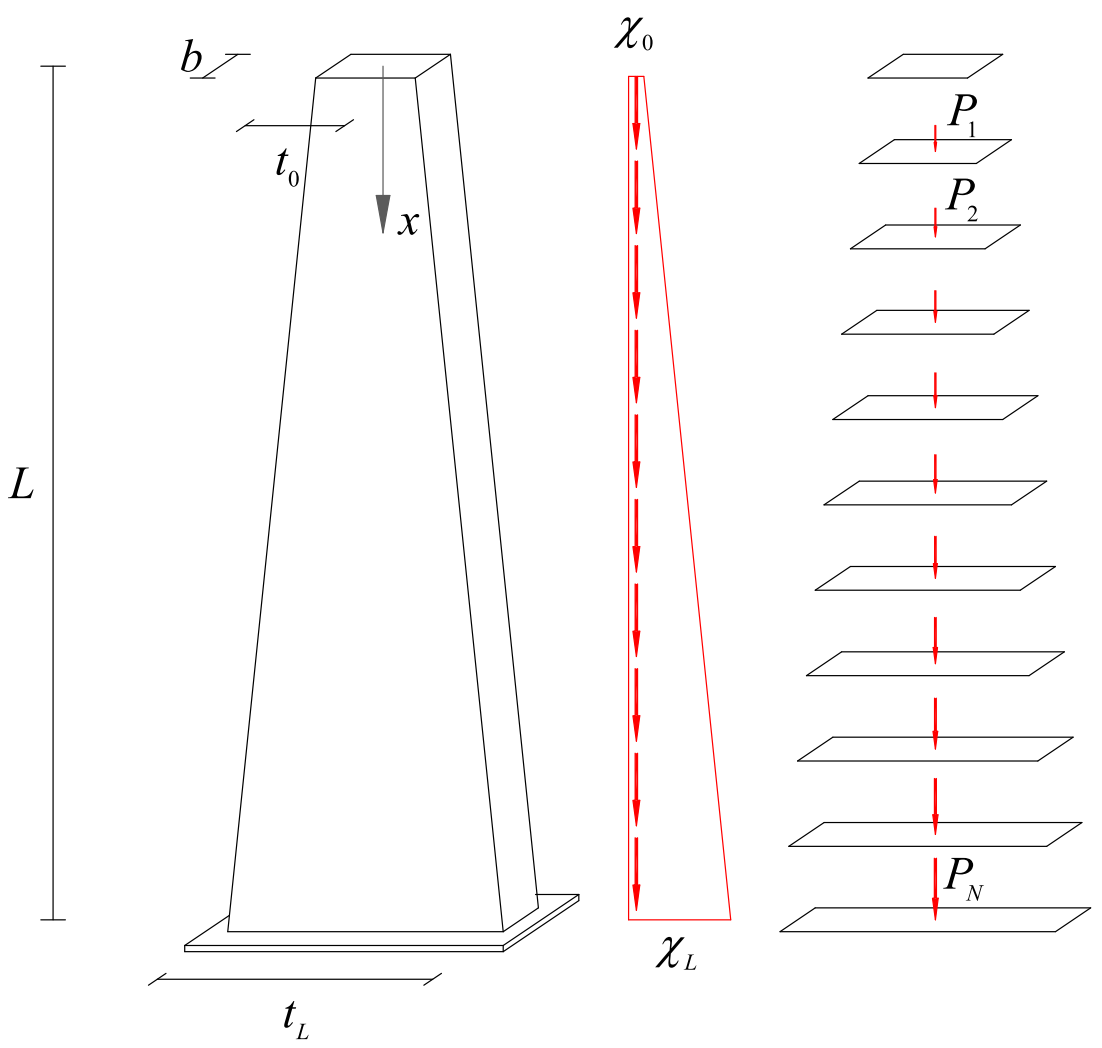

Fig. 8. Non-prismatic column under self-weight and corresponding discrete model with concentrated forces.

umns under self-weight $\chi$. This problem was addressed by Keller and Niordson [36] and Cox and McCarthy [37] who maximized the buckling capacity over a large class of assigned shapes that allows for the possibility of vanishing cross-sectional areas in the column domain.As shown in Fig. 4, the effect of self-weight load can be taken into account by considering a distributed axial load varying, for any constant density $\rho$, with a law proportional to volume. The numerical procedure for obtaining the critical load is straightforward even with the shape changing. It simply requires the integration of the distributed load over the length $a_{i}$ of the discretized column and the definition of the equivalent concentrated forces $P_{i}$ represented in Eq. (5). However, the discrete nature of the Hencky bar-chain model dictates the column shape to be defined at a finite number of cross-section areas. In such a case, it is possible to calculate the equivalent system of concentrated forces $P_{i}$ directly as:
$P_{i}=\rho A_{i} a_{i} \quad i=1 \ldots N$

The critical buckling load is obtained by increasing any concentrated load with a common parameter $\beta$ until $\beta=\beta_{c r}$.

Table 4 presents the non-dimensional critical buckling loads defined by

$\bar{\chi}=\chi_{0}^{c r} L^{3} / \rho E I_{0}$

and by considering HBM with discrete loads at $n=50$ and $n=100$ locations, and an area varying linearly as follows:

$A(x)=A_{0}((1-v)+v \xi)$

The corresponding second moment of area given by

$I(x)=I_{0}((1-v)+v \xi)^{3}$

with $w_{0}=w(x=0), A_{0}=A(x=0), I_{0}=I(x=0)$ and $v$ is a parameter governing the thickness taper ratio as shown in Fig. 8. It can be seen 


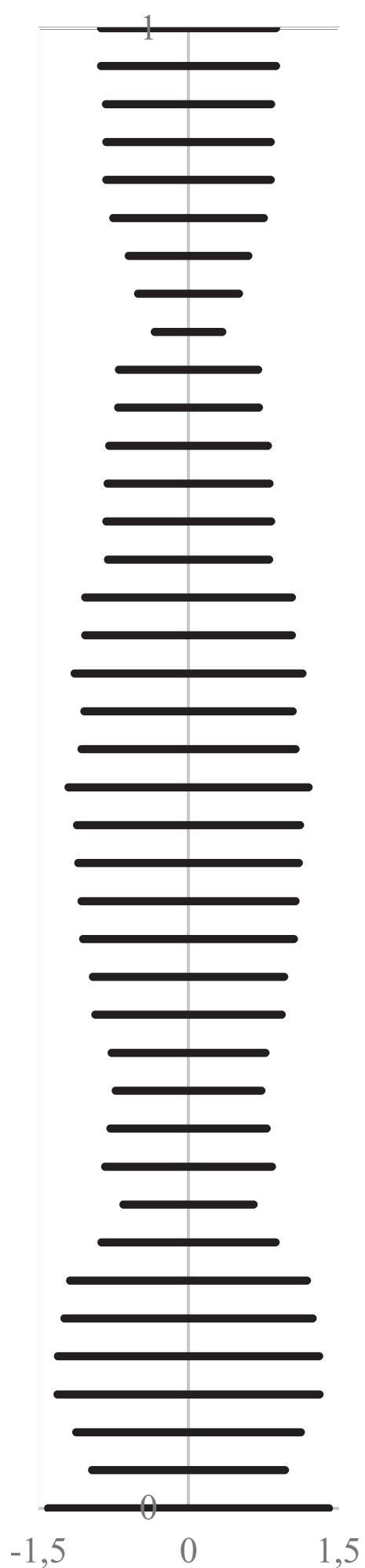

Fig. 9. Optimum design of a CC column under its own weight.

that the present results are in excellent agreement with those reported in the literature for homogeneous $[13,32]$ and inhomogeneous [37] columns.

Fig. 9 presents the optimal shape of a clamped ended column with an initial area $A_{0}=A_{\text {TOT }} / N$ and under its own weight. In such a case, we obtained a buckling load parameter

$\bar{\omega}=\frac{\int_{L} \omega_{c r}}{\int_{L} \omega_{c r}^{\text {hom }}}=1.37$
It can be seen that the critical buckling load that is 37\% higher than the value obtained from an equivalent uniform column under its own weight.

\subsection{Example 4. Optimization of stepwise columns under end concentrated load}

The final example is concerned with the optimization of stepwise columns subjected to a concentrated end force, obtained by varying the sectional length and area $\left(L_{i}, A_{i}\right)$ and keeping constant the overall length $L$ and area $A$. Fig. 10 shows the different stepwise columns considered.

In view of the discrete nature of the proposed method, the continuous parameter $L_{i}$ has to be substituted by the number of segments $n_{i}$ (see Fig. 10) characterized by a constant area $A_{i}$, so that the optimization requires the definition of a discrete number of parameters $n_{i}$ and the continuous one $A_{i}$ (that is, the radius $r_{i}$ for circular sections) under the conditions:

$$
\begin{aligned}
& \sum L_{i}=L \Rightarrow \sum n_{i}=n \\
& \sum A_{i} L_{i}=V \Rightarrow \sum n_{i} A_{i}=V
\end{aligned}
$$

where $n$ is the total number of segments considered in the discretized model (in the examples, we adopted $n=50,100$ ) and $V$ is the given total volume. We assume a total length $L=1$ and a volume $V=\pi$. The optimal buckling loads for the stepwise columns, as shown in Fig. 10, are presented in Table 4 for CF columns and Table 5 for CC columns, where $s_{2}, s_{3}$ and $s_{4}$ represent 2,3 and 4 stepwise, respectively. The results have been compared with the analytical ones obtained by Maalawi [20]. It can be seen that the optimal shape and critical buckling loads are in close agreement (within a few percent differences). With regard to the CF column, the optimal design furnishes gains in the critical buckling load by $20.53 \%$ for 2 stepwise (very close to the $20.79 \%$ obtained analytically in [22]), and by $28.86 \%$ for 4 -stepwise. Better results may be obtained by considering larger number $n$ of segments.

Malaawi [22] highlighted that for CC columns (and, in general, for any stepwise column characterized by symmetrical boundary conditions), the optimum design requires symmetrical mass and stiffness distributions about the mid-span. Therefore, it is not possible to increase the buckling performance of symmetrical $s_{2}$ columns, for which the best shape coincides with the homogeneous ones. For such a case, and for both the number of segments considered, the computer program gave different values of $\left(L_{1}, L_{2}\right)$ lengths, and a radius that was very close to unity, and thus the results reported in Table 5 are the approximate solutions compared with the analytical ones $\left(r_{1}, L_{1}\right)=\left(1 L_{1}\right),\left(r_{2}, L_{2}\right)=\left(1,1-L_{1}\right)$ proposed in the literature. Symmetrical results have been obtained for both $s_{3}$ and $s_{4}$ columns, with a modest gain in the critical buckling load (about $5 \%$ for the considered example). The shape is close to the uniform column.Next, we consider the parameter optimization of a stepwise column partially constrained to maintain a constant shape for an assigned segmental length $\lambda$ as shown in Fig. 11. The column is subjected to an end concentrated load $F_{0}$. We consider two stepwise columns with shape constraint over the segmental length $a$ (where $\lambda=[L / 2, L]$ or $\lambda=[0, L / 2]$ ) and the boundary conditions are CF and SS. Fig. 12 presents the optimal buckling loads $\Pi$ and the corresponding optimal column designs. As expected, there is no difference in the buckling load of the SS column with respect to the partitioning of segmental length $\lambda$. Also the optimal shapes are the same (just that they are inverted with respect to each other). The gain in the critical buckling load is about $13 \%$ over its equivalent uniform column counterpart. For the CF column case, two different column designs were obtained by varying $\lambda$. When $\lambda=[L / 2, L]$, that is the column segment to be optimized is closest to the constraint where the curvature is 

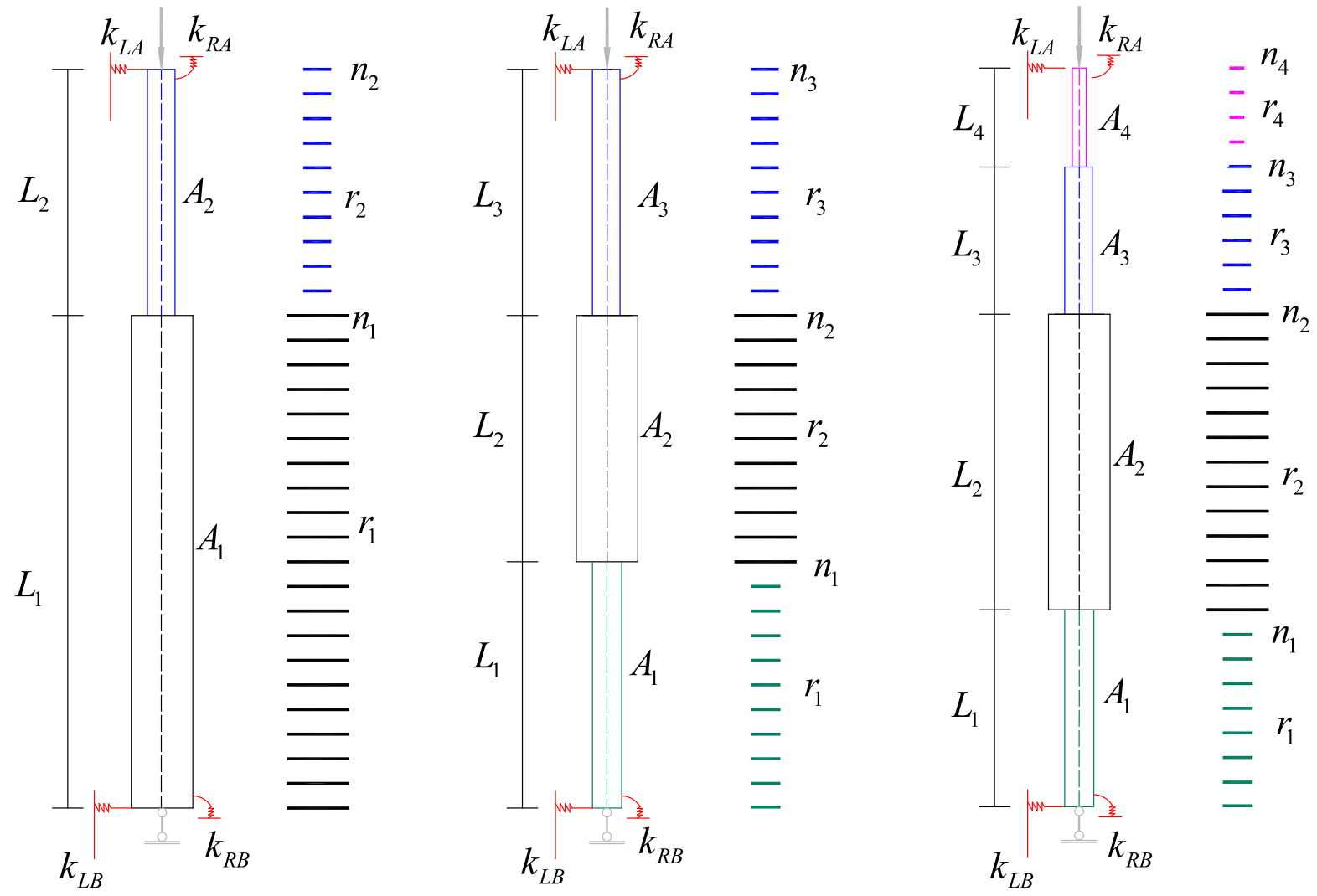

Fig. 10. Two, three and four stepwise columns and equivalent discrete columns for optimization.

Table 5

Optimum design of stepwise CC columns.

\begin{tabular}{lllll}
\hline $\begin{array}{l}\text { Stepwise } \\
\text { column }\end{array}$ & $\mathrm{N}$ & 50 & 100 & {$[22]$} \\
\hline$s_{2}$ & $\left(r_{1}, L_{1}\right)$ & $\left(1.12, L_{1}\right)$ & $\left(1.12, L_{1}\right)$ & $\left(1, L_{1}\right)$ \\
& $\left(r_{2}, L_{2}\right)$ & $\left(0.97,1-L_{1}\right)$ & $\left(0.97,1-L_{1}\right)$ & $\left(1,1-L_{1}\right)$ \\
& $\Pi$ & 1.025 & 1.025 & 1.0000 \\
$s_{3}$ & $\left(r_{1}, L_{1}\right)$ & $(0.9449,0.34)$ & $(0.95001,0.35)$ & - \\
& $\left(r_{2}, L_{2}\right)$ & $(1.1079,0.32)$ & $(1.1084,0.30)$ & - \\
& $\left(r_{3}, L_{3}\right)$ & $(0.9449,0.34)$ & $(0.95001,0.35)$ & - \\
& $\Pi$ & 1.0518 & 1.0542 & - \\
$s_{4}$ & $\left(r_{1}, L_{1}\right)$ & $(1.1153,0.15)$ & $(1.1168,0.15)$ & $(1.125,0.1688)$ \\
& $\left(r_{2}, L_{2}\right)$ & $(0.9463,0.35)$ & $(0.9455,0.35)$ & $(0.9375,0.3312)$ \\
& $\left(r_{3}, L_{3}\right)$ & $(0.9463,0.35)$ & $(0.9455,0.35)$ & $(0.9375,0.3312)$ \\
& $\left(r_{4}, L_{4}\right)$ & $(1.1153,0.15)$ & $(1.1168,0.15)$ & $(0.9375,0.3312)$ \\
& $\Pi$ & 1.0578 & 1.0592 & 1.05477
\end{tabular}

greater, it is not possible to obtain a gain greater than $1.6 \%$ over the uniform column counterpart. When $\lambda=[0, L / 2]$, the gain may be increased to about $6 \%$.

Better results may be achieved by increasing the number of stepwise segments and reducing the dimension of the constrained segmental geometry, as shown by the results presented in Fig. 13 where $\lambda=[0, L / 3], \lambda=[L / 3,2 L / 3]$ and $\lambda=[2 L / 3, L]$. The improvement in the buckling load varies between $10 \%$ and $24 \%$.

\section{Concluding remarks}

This paper presents a simple and powerful formulation for the optimization of columns against buckling by adopting the Hencky bar chain model (HBM) and the genetic algorithms (GA). The HBM-GA method was tested on non-uniform columns under both

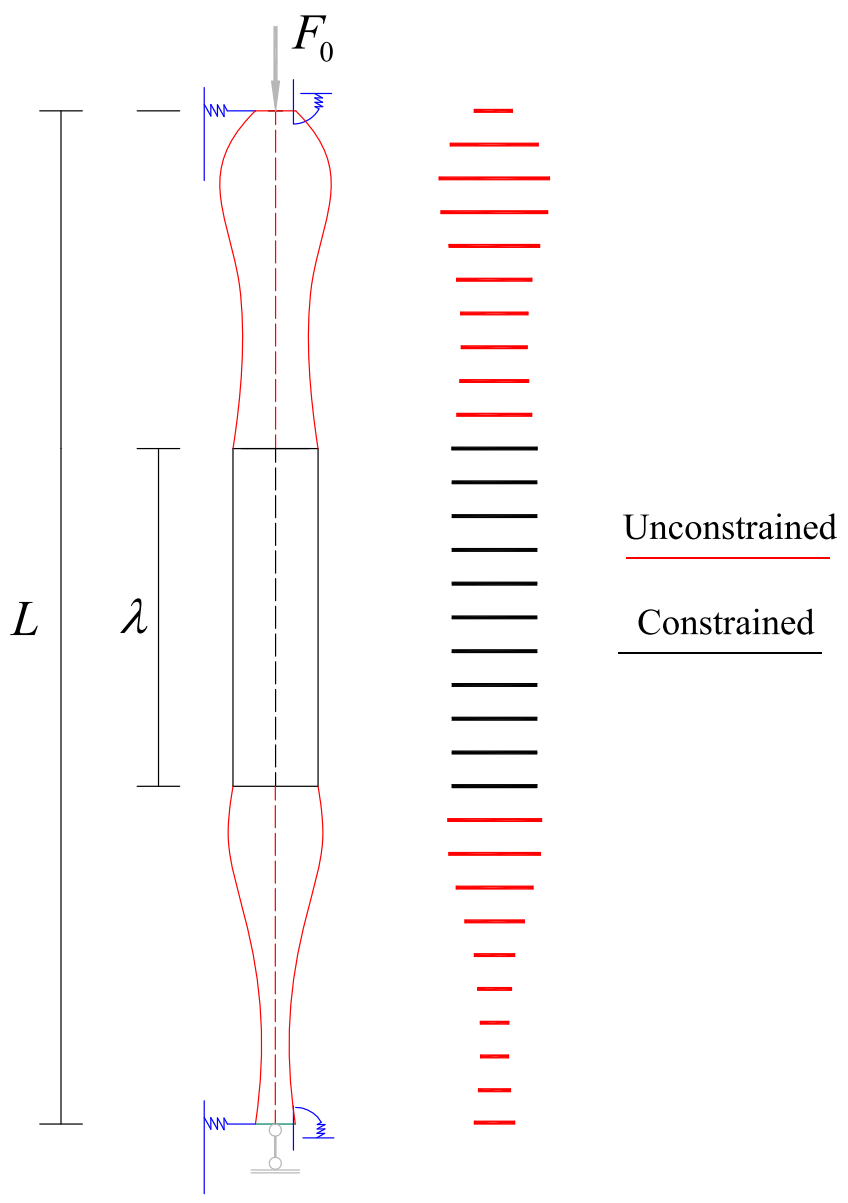

Fig. 11. Partially constrained column. 

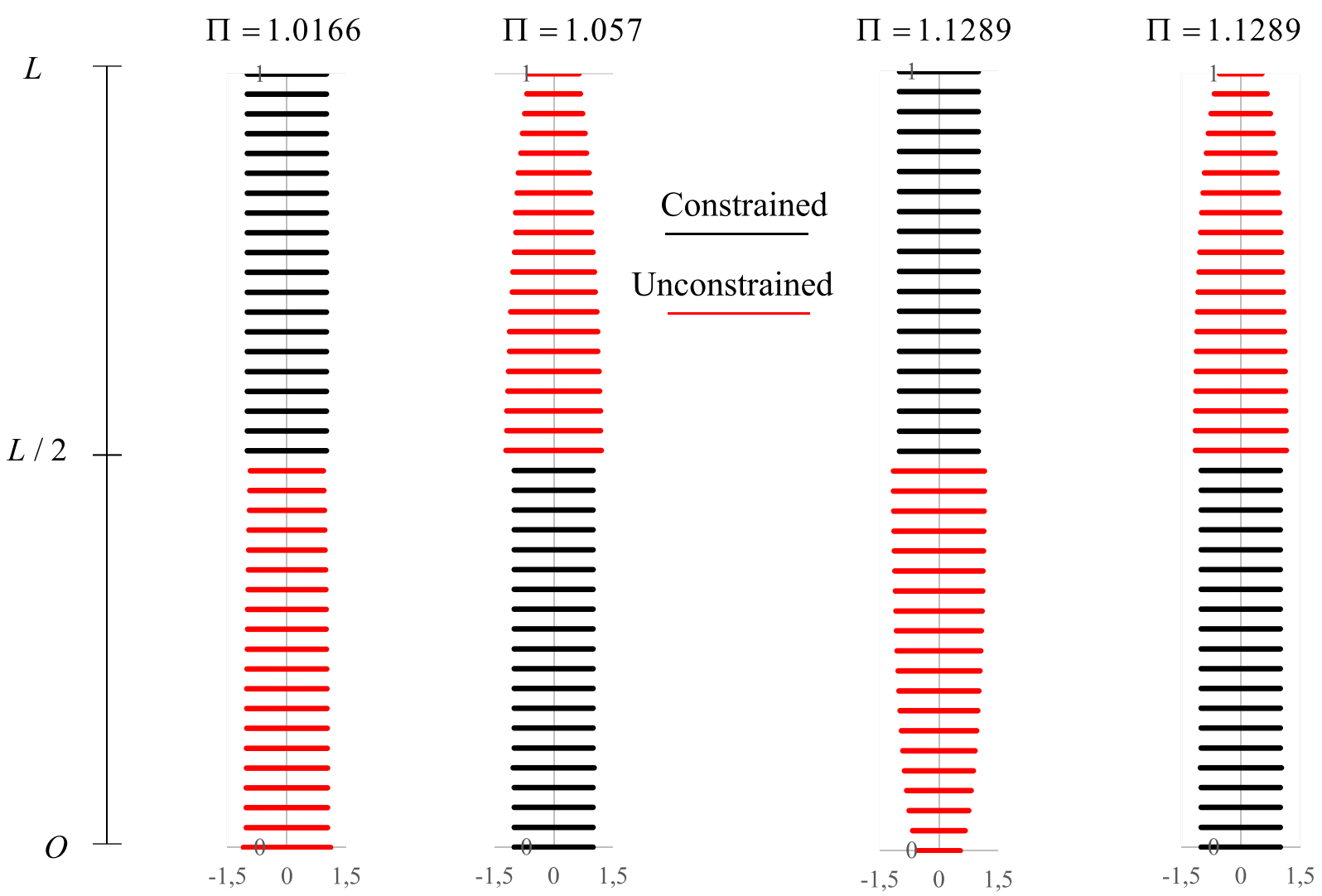

$C F$

Fig. 12. Optimal profile of two stepwise partially constrained column.
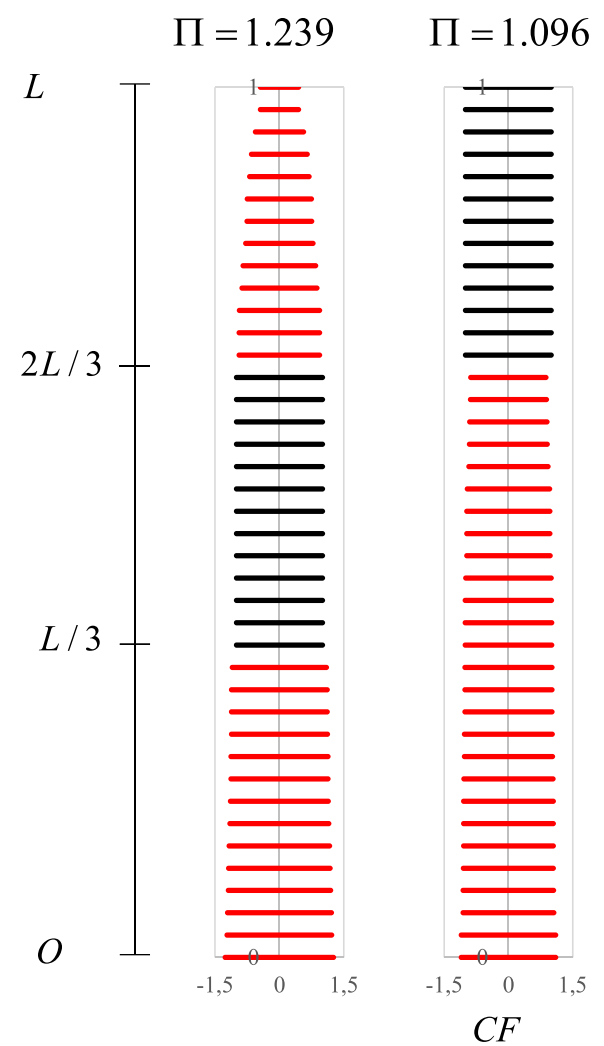

$\Pi=1.122$

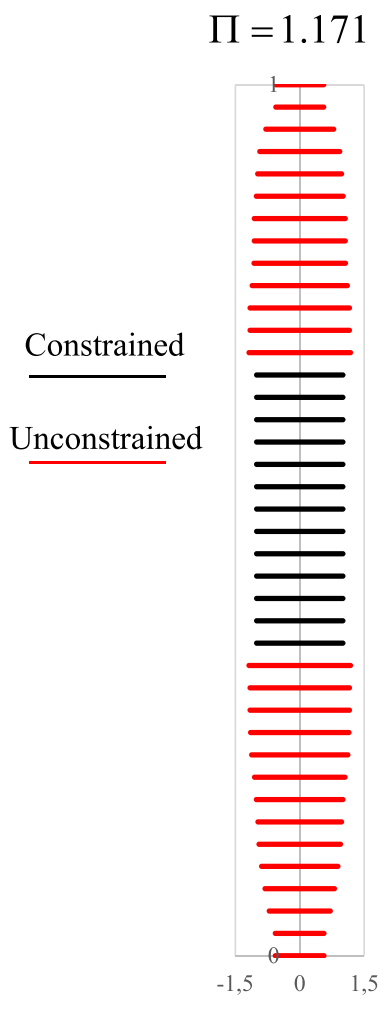

$\Pi=1.221 \quad \Pi=1.221$

Fig. 13. Optimal shape of three stepwise partially constrained column.

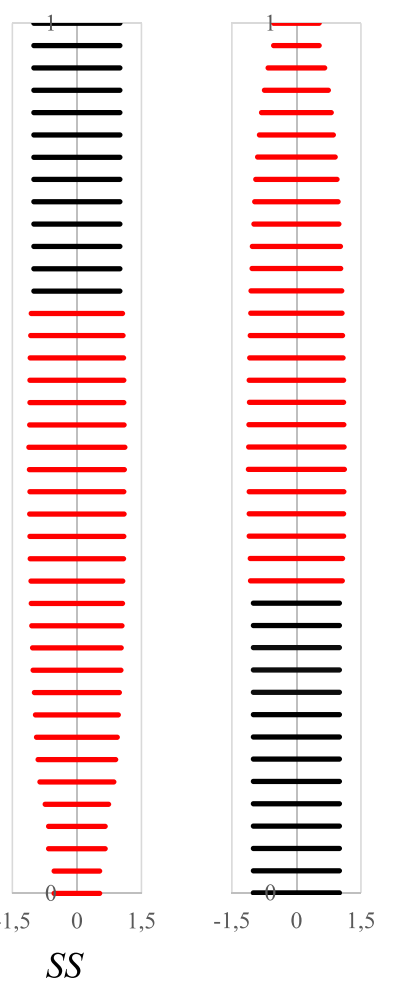


concentrated and distributed loads, including self-weight. Several column examples were presented and the optimal solutions were verified by existing results; thereby confirming the convergence, accuracy and validity of the HBM-GA method. It is worth noting that at least 40 segments are needed for the HBM model for capturing the non-uniform variation of the cross-sectional area (or second moment of area). The numerous optimal column designs presented herein should provide useful benchmark solutions to check other new numerical methods for column optimization. The method is clearly excellent for optimizing the joint stiffnesses of articulated columns against buckling since the HBM is a natural model for such articulated columns.

\section{Appendix A}

The coefficients $\left(\phi_{i}, \gamma_{i}, \kappa_{i}, \eta_{i}\right)$ represented in Eq. (6) assume the explicit form:

$$
\begin{aligned}
& \phi_{i}=\frac{C_{i-1}}{C_{i+1}} ; \quad \gamma_{i}=\frac{\alpha_{i-1} C_{i-1}-2\left(C_{i-1}+C_{i}\right)}{C_{i+1}} ; \quad \kappa_{i}=\frac{\alpha_{i} C_{i}-2\left(C_{i}+C_{i+1}\right)}{C_{i+1}} ; \\
& \eta_{i}=\frac{C_{i-1}+4 C_{i}+C_{i+1}-\alpha_{i-1} C_{i-1}-\alpha_{i} C_{i}}{C_{i+1}} ;
\end{aligned}
$$

In terms of the stiffnesses $C_{j}=E I_{j} / a$ and the applied loads $\alpha_{j}=P_{j} a^{2} / E I_{j}$.

The boundary conditions (7) and (8) are defined by the coefficients:

$$
\begin{aligned}
& \eta_{0}=\frac{C_{1}+C_{R A}+C_{L A} a^{2}-\alpha_{0} C_{0}}{C_{1}} ; \quad \kappa_{0}=\frac{\alpha_{0} C_{0}-C_{R A}}{C_{1}}-2 ; \quad \kappa_{1}=\frac{\alpha_{1} C_{1}-2\left(C_{1}+C_{2}\right)}{C_{2}} ; \\
& \gamma_{1}=\frac{\alpha_{0} C_{0}-C_{R A}-2 C_{1}}{C_{2}} ; \quad \eta_{1}=\frac{4 C_{1}+C_{2}+C_{R A}-\alpha_{0} C_{0}-\alpha_{1} C_{1}}{C_{2}} ; \\
& \gamma_{n-1}=\alpha_{n-1}-2-2 \frac{C_{n-1}}{C_{n-2}} ; \quad \eta_{n-1}=4 \frac{C_{n-1}}{C_{n-2}}+1+\frac{C_{R B}}{C_{n-2}}-\frac{\alpha_{n-1} C_{n-2}+\alpha_{n} C_{n-1}}{C_{n-2}} ; \\
& \kappa_{n-1}=\frac{\alpha_{n} C_{n-1}-C_{R B}-2 C_{n-1}}{C_{n-2}} ; \quad \eta_{n}=\alpha_{n}-\frac{C_{R B}}{C_{n-1}}-2 ; \quad \kappa_{n}=1+\frac{C_{R B}}{C_{n-1}}+\frac{C_{L B} a^{2}}{C_{n-1}}-\alpha_{n} ;
\end{aligned}
$$

\section{References}

[1] Eisenberger M. Buckling loads for variable cross-section members with variable axial forces. Int J Solids Struct 1991;27:135-43.

[2] Elishakoff I. Inverse buckling problem for inhomogeneous columns. Int J Solids Struct 2001;38:457-64.

[3] Ruocco E, Mallardo V. Buckling analysis of Levy-type orthotropic stiffened plate and shell based on different strain-displacement model. Int J Non-Linear Mech 2013;50:40-7.

[4] Ruocco E, Minutolo V. On initial postbuckling of composite plates assemblies by semianalytical procedure. Mech Compos Mater Struct 2001;8(1):1-14.

[5] Ruocco E, Minutolo V, Ciaramella S. A generalized analytical approach for the buckling analysis of thin rectangular plates with arbitrary boundary conditions. Int J Struct Stab Dyn 2011;11(1):11-21.

[6] Li WL. Free vibrations of beams with general boundary conditions. J Sound Vibr 2000;237(4):709-25.

[7] Huang Y, Luo Q-Z. A simple method to determine the critical buckling loads for axially inhomogeneous beams with elastic restrains. Comput Math Appl 2011;61:2510-7.

[8] Hencky H. Uber die angenäherte Lösung von Stabilitätsproblemen im Raummittels der elastischen Gelenkkette. Der Eisenbau 1920;11:437-52 [in German].
9] Silverman IK. Discussion on the paper of "Salvadori M.G., Numerical computation of buckling loads by finite differences, Transactions of the ASCE, 116, 590-636, 1951, Transactions of the ASCE 116: 625-626; 1951.

[10] Leckie FA, Lindberg GM. The effect of lumped parameters on beam frequencies. Aeronaut Q 1963;14:224-40.

[11] Challamel N, Kocsis A, Wang CM. High-order gradient elasticity models applied to geometrically nonlinear discrete system. Theoret Appl Mech 2015;42(4):223-48.

[12] Wang CM, Zhang H, Gao RP, Duan WH, Challamel N. Hencky bar-chain model for buckling and vibration of beams with elastic end restraints. Int J Str Stab Dyn 2015;15:1540007.

[13] Duan WH, Wang CM. Exact solution for buckling of columns including selfweight. J Eng Mech 2008;134(1):116-9.

[14] Love AEH. A treatise on the mathematical theory of elasticity. 4th ed. Ney York: Dover publications; 1944.

[15] Clausen T. Über die form architektonischer säulen. Bull Phys Mathém l'Académie St Petersburg 1851;9:368-79.

[16] Keller JB. The shape of the strongest column. Arch Ration Mech Anal 1960;5:275-85.

[17] Tadjbakhsh I, Keller JB. Strongest columns and isoperimetric inequalities for eigenvalues. J Appl Mech 1962;29(1):154-64.

[18] Olhoff N, Seyranian AP. Bifurcation and post-buckling analysis of bimodal optimum columns. Int J Solids Struct 2008;45:3967-95.

[19] Seyranian, AP. On a problem of Lagrange. Izv. AN SSSR. Mekhanika Tverdogo Tela (English translation: Mech. Solids), 19(2): 101-111; 1984.

[20] Olhoff N, Rasmussen SH. On single and bimodal optimum buckling loads of clamped columns. Int J Solids Struct 1977;13:605-14.

[21] Li XF, Xi LY, Huang Y. Stability analysis of composite columns and parameter optimization against buckling. Compos B 2011;42:1337-45.

[22] Maalawi KM. Buckling optimization of flexible columns. Int J Solids Struct 2002;39:5865-76.

[23] Atanackovic TM, Simic SS. On the optimal shape of a Pflüger column. Eur J Mech A 1999;18:903-13.

[24] Novakovic B. Optimal shape of a column with clamped-elastically supported ends positioned on elastic foundation. Theoret Appl Mech 2015;42 (3): $191-200$

[25] Holland JH. Adaptation in natural and artificial systems: University of Michigan Press (2nd ed., MIT Press); 1992.

[26] Dai H, Yang Y, Li H, Li C. Bi-directional quantum crossover-based clonal selection algorithm and its applications. Expert Syst Appl 2014;41 (16):7248-58.

[27] Nguyen HX, Lee J, Vo T, Lanc D. Vibration and lateral buckling optimisation of thin-walled laminated composite channel-seciotn beams. Comput Struct 2016:143:84-92.

[28] Iuspa L, Ruocco E. Optimum topological design of simply supported composite stiffened panels via genetic algorithms. Comput Srtuct 2008;86:1718-37.

[29] Ehsani A, Rezaeepazhand J. Stackling sequence optimization of laminated composite grid plates for maximum buckling load using genetic algorithm. Int J Mech Sci 2016;119:97-106.

[30] Krishna SG, Ram YM. Discrete model analysis of optimal columns. Int J Solids Struct 2007;44:7307-22.

[31] Ruocco E, Zhang H, Wang CM. Hencky bar-chain model for buckling analysis of non-uniform columns. Structures 2016;6:73-84.

[32] Zhang H, Wang CM, Ruocco E, Challamel N. Hencky bar-chain model for buckling and vibration analyses of non-uniform beams on variable elastic foundation. Eng Struct 2016;126:252-63.

[33] Wang CM, Ang KK. Buckling capacities of braced heavy columns under an axial load. Comput Struct 1988;28(5):563-71.

[34] Lingiun W, Tianbing T, Xianghong X, Wenjie S. Truss optimization on shape and sizing with frequency constraints based on parallel genetic algorithm. Struct Multidiscip Optim 2010;43(5):665-82.

[35] Zhang H, Wang CM, Challamel N, Ruocco E. Semi-analytical solutions for optimal design of columns based on Hencky bar-chain model. Eng Struct 2017; 136:87-99.

[36] Keller JB, Niordson FI. The tallest column. J Math Mech 1966;16:433-46.

[37] Cox SJ, McCarthy CM. The shape of the tallest column. SIAM J Math Anal $1998 ; 29(3): 547-54$.

[38] Wei DJ, Yan SX, Zhang ZP, Li XF. Critical load for buckling of non-prismatic columns under self-weight and tip force. Mech Res Commun 2010;37:554-8. 